\title{
THE PERCEIVED EFFECTIVE MOTIVATION METHODS IN CHINA'S CREATIVE INDUSTRIES: THE MANAGERIAL PERSPECTIVE
}

\author{
Yuet-Kai Chan ${ }^{a}$, Henry Ma ${ }^{b}$ \\ ab The Hong Kong Polytechnic University, Hong Kong, China \\ Corresponding email: amelieyk.chan@connect.polyu.hk
}

\begin{abstract}
Developing China's creative industries are being prioritized as one of the solutions for maintaining the competitive advantage in order to sustain China's economic growth. Motivating creative workers became one of the major issues that Chinese creative organziations ought to manage. Studies show that the higher motivation employees have, the better they perform. But motivating creative workers may have different requirement comparing to get general employees. Motivating employees' creative performance is quite a popular topic in organizational behavior study in western countries. However, motivation of Chinese creative workers remains less explored. This study seeks to fill this knowledge gap by investigating the current motivation methods that are being used in China's creative industries and the effective methods perceived by managerial level people. Qualitative research approach is employed as the methodology.Semi-structured interviews have been conducted with managers of creative organizations in China. Although some previous studies indicated that intrinsic motivation is more effective in motivating creativity than extrinsic motivation, the current findings show that tangible rewards and recognition are the most effective motivation methods perceived by managers. This study tried to reveal the management problems of motivating Chinese creative workers. Cultural background, economic factors and managers' knowledge background may be the reasons for the current findings.
\end{abstract}

Keywords: China's Creative Industries, Motivation, Organizational Behavior.

\section{Introduction}

Chinese organizations have been Original Equipment Manufacturer (OEM) for foreign companies since the economic reform. Due to rapid economic growth, they are losing their advantage of low labor cost. Chinese government started to stress strong effort on stimulating China's creative industries in order to maintain sustainable development from the year 2006. The preferential policies were proposed in almost every year plan for encouraging creative companies to transform themselves from OEM to Original Design Manufacturer (ODM) or Original Brand Manufacturer (OBM).

As one of the results of developing creative industries in China, more than three hundred thousand arts and design graduates become creative workers increative industries every year. Their creative performance are crucial in helping creative organizations to stay competitive in the transformation process. If creative organizations want to maximize their employees' creative performance, appropriate motivation methods should be employed. In organizational behavior study, motivation study is an important topic. Studies show that the higher motivation employees have, the better they perform (Din et al., 2014). At the same time, motivation is found as one of the key components of creativity (Amabile, 1983, Sternberg \& Lubart, 1991). Scholars consider it has very close relationship with creative performance. They stated that motivation governed a person's willingness to be creative 
(Stein, 1953; Hennessy \& Amabile, 2010, Casakin and Kreitler, 2010).

However, motivating creative workers may need different strategy comparing with general employees. Some studies indicated that intrinsic motivation is more effective in motivating creativity than extrinsic motivation (Dewett, 2007), which means extrinsic rewards that a company usually use may not be the most effective methods for improving creative performance.So, what are the China's creative industries do to motivate their creative workers? Are the organizations using effective methods to motivating employees' creative performance?

\section{Research Objective and Significant}

In western countries,motivating employees' creative performance is quite a popular topic in organizational behavior study. But little research could be found regarding China's creative industries. This study seeks to fill this knowledge gap by revealing the current motivation methods in China's creative industries. This research will answer two questions:

1. What are the current motivation methods that China's creative industries are using?

2. What are the effective methods of motivating creative workers perceived by the management?

The findings are believed to reveal the management issue in motivating Chinese creative workers. It strives to enrich knowledge in the field. It also intends to help company managers and policy makers in China's creative industries to better understand their problems.

\section{Literature Review}

\subsection{Motivation}

The word "motivation" was from a Latin word "movere" meaning, "to move" (Helou \&Viitala, 2007). In 1982, Mitchell described motivation as the goad to action(Mitchell,1982). Yang (1986) explained that "motivations have much to do with providing reasons forchoosing different courses of actions and performing with different degrees of efforts,pertaining to man's desires, wants, perceived needs and thus purpose" (Yang, 1986, p.86). Most of the studies divided motivation into extrinsic motivation and intrinsic motivation. The distinction based on the kind of reward people expect from completing a task (Oudeyer \& Kaplan, 2008). Extrinsic motivation means one engaged in an activity because it has instrumental value. This value is either tangible or intangible rewards from external, such as money or recognition (Locke \& Latham, 1990).Intrinsic motivation is defined as "the inherent tendency to seek out novelty and challenges, to extend and exercise one's capacities, to explore, and to learn". (Ryan \& Deci, 2000, p. 70). Studies suggested that these two types of motivation lead to very different consequences of a task. Most of the general tasks can be motivated be extrinsic motivation. However, for creativity related task, such as exploration or seeking for challenge, intrinsic motivation could have positive effect while extrinsic motivation may possibly undermine creative performance ( Amabile et al., 1994).

\subsection{Motivation in Workplace}

Motivation in organizational behavior study can be traced back to the 5oth century or even earlier. Huge numbers of research have been conducted regarding many difficult aspects of motivation in organization. These studies indicated that understanding what factors affects employees' motivation toward their job is one of the major management issues(Din et al., 2014). It is because motivated employees put extra effort in their job and perform better, which eventually maximize company's performance(Lather \& Jain, 2005). So, managers need to carry out management strategy that can keep their employees motivated.

By reviewing motivation studies, they divided factors affecting employees' motivation into two types of influences, individual influence and social influence (Kanfer \& Chen, 2016). Individual influence mainly about the intrinsic motives of employees, which related to the needs, wants or traits of an individual, such as autonomy, growth, competence.There are 
some widely used theories developed, for instance, Alderfer's Existence-Relatedness-Growth Theory (Alderfer, 1969), McClelland theory of needs (McClelland, 1987), Cognition Evaluation Theory (Ryan \& Deci, 2000). Social influence refers to the extrinsic effects that affect employees' motivation toward their job. It is related to things that can affect people social relationship, such as their demands of the job, social interactions with colleagues and supervisors, the social structure of their work. Important theories included Job characteristics Theory (Hackman \& Oldham, 1976), Adam's equity theory(Adam, 1965) and Theories of leadership (Coloquitt et al., 2005).

\subsection{Motivating Creative Workers}

Although motivation plays one of the major roles in organizational behavior, managers are facing some difficulties as employees are diverse and motivated by different things (Lather \& Jain, 2005), especially for creative workers. Since motivation is one of the key components of creativity, it has influential power on creativity. Many research and theories focus more on intrinsic than extrinsic motivation. They think intrinsic motivation can better motivate employees creative performance (Collins \& Amabile, 1999).For instance, Amabile (1996) stated that interest and liking the task make the best motivation to creative workers, which can even help to explore their creative potential.

If that is the case, it seems impossible for company managersto manipulate employees' interestdirectly. So, Ryan and Deci (2000) found that somehow, extrinsic motivation could be integrated and internalized to become intrinsic motivation. For example, supervision from a team leader is typically an extrinsic social influence. But, if the supervision provides positive and useful information that could help people pursuing their intrinsic goal, like personal growth, the team member could still be motivated (Ryan \& Deci, 2000). This indicated that the effectiveness of motivation methods, no matter intrinsic or extrinsic, depends on some contextual information.

\subsection{Motivating Chinese Employeesand Creative Workers}

When comparing with motivation studies in western countries, some significant differences have been found in China's motivation studies (Burton et al, 2013). These studies included research reviewsof existing motivation theories from China's perspective (Geren, 2011).; or comparing Chinese employees' motivationto other regions (Fisher and Yuan, 1998, Jackson $\& B a k, 1998)$. Most of these research findings indicated that political, economic and cultural factors have to be considered. For motivating employees' creativity, most of the studies focused on the influence of one or two factors. These factors included work support (Wang et al, 2010), leadership (Zhong, 2013; Pei et al., 2013, Fang, 2014; Guo \& Duan, 2008), task diversity (Jiang \& Yang, 2014), learning goal orientation (Wang et al., 2015) and environment (Hon, 2012).

However, very few empirical studieshave been conducted within China's creative industries. Most of them are literature reviews and phenomenon analysis(Zhang 2014). These studies suggested that although political, economic and cultural environment are influencing Chinese employees' motivation, the influencing factors may stillvary under the tremendous economic development in China. People's work value might shift according to the environmental changes(Fisher \& Yuan, 1998). Therefore, this study seeks to gain a deeper understanding of how China's creative organizationsmotivate their creative workers under these environmental changes.

\section{Research Design}

With the goal of revealing the current motivation methods in China's creative industries, qualitative research approach has been employedto explore this topic. Since the development of China's creative industries were better developed inthe representative first-tier city, Beijing and Shenzhen, China, nine companies from these cities were selected to participate in the data collection. They are local Chinese private enterprise from seven types of creative oriented companies. It included film production company, animation company, game design 
company, new technology design company, post-production company, Interactive design company and creative marketing company. Participants included managerial level people, such as top management people and team managers.

Based on the literature review, semi-structured questionnaire was used as the guideline in the interview process. The questionnaire contained three parts. First part is the demographic data. Second is the filter questions regarding whether they consider creativity as one of the required ability of their employees or not. The third part is about motivation methods that they are currently practicing in their company.

Data collection have been finished through in-depth interviews within two months in early 2017. All interviews were recorded and transcripted. MAXQDA is employed for coding and data analysis.

\section{Findings \\ 5.1 Demographic Data}

One participant from each of those nine companies was interviewed. Theiragesrangedfrom 23 - 41 years old and the majority are 30 - 34 years old. They included design team managers, film directors and owners of small company. Most of them have 8-15 years working experience and they were promoted to the current management position from designers or workers.

\subsection{Finding 1: Current Motivation Methods}

The current motivation methods can be divided into two parts. One is the method that are officially stated in company policy and the other part is some motivation methods managers design and used by themselves. The results show that three types of methods are currentlycarried out by these creative companies.

1) The most common one is tangible rewards, which included salary, commission and other monetary rewards.

2) Half of these managers mentioned about the appraisal.

3) One of them talked about the training that can bring opportunity for personal growth. There are six motivation methods that are currently used by managers.

a) Majority of these managers tried to offer learning and personal growth opportunities to their employees, which included peer learning, experience sharing and helping employees to set up and reach their personal goals.

b) The second method is building up employees' confidence by recognizing and appropriating their work, for instance, public praise.

c) Some managers mentioned about a happy working atmosphere is the key for them to motivate their employees.

d) Some of them also manage to keep the task freshness and support their employees to try new things in order to have them motivated.

e) Managers also mentioned about their flat management strategy, which encouraged their employees to express their idea freely.

f) A few managers consider clear working procedure isone of their motivation strategies.

\subsection{Finding 2: Perceived Effective Motivation Methods}

When asking participants about what is the most effective method they perceived, four methods are mentioned.

i) Monetary rewards are considered as the most effective one.

ii) Recognition is the second effective motivation method perceived by managers. 
iii) Some managers think providing training and growing opportunity for employees can effectively motivate their employees.

iv) A few of them think good prospect and happy atmosphere play an important role in employees' motivation.

\section{Discussions}

The above findings indicated that there are only very few motivation methods that are currently being used in these creative companies. All of them are traditional methods without surprise. Very little of these companies have a systematic strategy in motivating their creative workers. The major reasons may refer to the management abilities and background experiences of the managerial people. Most of the creative organizations in China started up by designers or artists who were originally an expert of design or art production. Their management or administration knowledge is relatively weak. Therefore, they do not pay much attention in setting up systematic policy to motivate their employees. Same as the midlevel managers, they are usually promoted from design or production team. All the motivation methods they used are simply carried out by their perception, instead of base on management knowledge.

The current findings shows contradiction with previous studies about extrinsic motivation may have negative effect on creative workers' performance.Among all the motivation methods mentioned in our findings, the most popular one is tangible rewards. It is also the most effective method perceived by managers. Tangible rewards here mainly referred to monetary rewards like salary and commission, which are typical extrinsic motivation. This finding The importance of monetary rewards is strongly related the rapid economic growth in China. Companies are using commission strategies to motivate their creative workers. Comparing to the current living standard and property price, almost every creative workers are underpaid. They are willing to work harder for sustaining their living in first-tier cities. Therefore, monetary rewards became the most effective motivation method.

Recognition is the second most effective motivation method perceived by managers. They tried to motivate their employees by praising or verbally confirming their abilities when they work well. With collectisivm cultural background, people are supposed to be interdependence. They should be more emphasis on the group contribution, instead of personal recognition (Wei et al., 2010). The perceived effectiveness of recognition in our findingis in contradiction to this traditional cultural background. It obviously shows that Chinese culture is gradually changing. For now, managers considered giving public recognition could effectively motivate their employees. One of the reason may refer to China's one-child policy that started in 1982. Majority of managers and working class are now the generation under this policy. They grew up as a relatively more self-centered person, which makes them less inclined to value the tradition of collectivist culture. Personal achievement became one of the important goals. Therefore, recognition is perceived as an effective motivation method.

\section{Conclusion}

With the findings discussed above, this study served the purpose by investigated the current motivation methods and identified monetary rewards and recognition as the most effective methods perceived by managers in China's creative industries. This study revealed some management problems in China's creative industries. First, managerial people lack management knowledge, which causes insufficient attention being paid on employees' motivation. Second, most of the current motivation methods are traditional methods. Managers of creative organizations haven't aware of the specialty of motivating creative workers. Moreover, cultural, economic factors and their changes have to be count in consideration. 
This empirical study provided a tentative overview of motivation in China's creative industries. It could help company managers and policy makers in China's creative industries to understand the current problems. Further research will be conduct to gain better insight in how to motivate Chinese creative worker with appropriate methods. 


\section{References}

i. Adam, J., 1965. Inequity in social exchange. In: L. Berkowitz, ed. Advances in experimental social psychology. New York: Academic Press, pp. 267-300.

ii. Alderfer, C., 1969. An empirical test of a new theory of human needs. Organizational Behavior \& Human Performance, 4(2), pp. 142-175.

iii. Amabile, T., 1996. Creativity in context: Update to'the social psychology of creativity', s.l.: Westview Press.

iv. Amabile \& Teresa, M., 1983. The social psychology of creativity: A componential conceptualization. Journal of personality and social psychology, 45(2), p. 357.

v. Amabile, T., Hill, K., Hennessey, B. \& Tighe, E., 1994. The Work Preference Inventory: assessing intrinsic and extrinsic motivational orientations. Journal of Personality and social psychology, 66(5), pp. 950-967.

vi. Burton, O. et al., 2013. A Comparison of America and China: Intrinsic v. Extrinsic Motivation and Cultural Influences', s.l.: s.n.

vii. Casakin, H. \& Kreitler, S., 2010. Motivation for creativity in architectural design and engineering design students: implications for design education'. International Journal of Technology and Design Education, 20(4), pp. 477-493.

viii. Collins, M. A. \& Amabile, T., 1999. I5 motivation and creativity': Handbook of creativity, s.l.: s.n.

ix. Coloquitt, J., Greenberg, J. \& Zapata-Phelan, C., 2005. What is organizational justice? A historical overview. In: J. Greenberg \& Coloquitt, eds. Handbook of organizational justice. Mahwah, NJ, US: Lawrence Erlbaum, pp. 3-56.

x. Dewett, T., 2007. Linking intrinsic motivation, risk taking, and employee creativity in an. $R \& D$ environment, 37(3), pp. 197-208.

xi. Din, M., Bashir, M., Cheema, K. \& Zafar, S., 2014. The Role of Power Distance in the Relationship between Employee Motivation and Organizational Commitment: A Study on Education Sector of Pakistan. Journal of Business and Management, 16(1), pp. 9-18.

xii. Fang 方雯, 王林雪, 冯耕中, 秦. \&\&张燕花, 2014. 内在动机, 管理者情绪智力与员工创造力矢系研 究--基于 3 类所有制企业_R\& D 背景的实证. 科技进步与对策, 31(7), pp. 142-148.

xiii. Fisher, C. \& Yuan, X., 1998. What motivates employees? A comparison of US and Chinese responses. International Journal of Human Resource Management, 9(3), pp. 516-528.

xiv. Geren, B., 2011. Motivation: Chinese theoretical perspectives. Journal of Behavioral Studies in Business, 3(1).

xv. Hackman, J. \& Oldham, G., 1976. Motivation through the design of work: test of a theory. Organizational Behavior \& Human Performance, 16(2), pp. 250-279.

xvi. Helou, S. \& Viitala, T., 2007. 2007,'How culture and motivation interacts? : - a cross-cultural study, s.l.: Crops.

xvii. Hennessey, B. \& Amabile, T., 2010. Creativity. The Annual Review of psychology, Volume 61, pp. 569-598.

xviii. Hon, A., 2012. Shaping environments conductive to creativity the role of intrinsic motivation. Cornell Hospitality Quarterly, 53(1), pp. 53-64.

xix. Jackson, T. \& Bak, M., 1998. Foreign companies and Chinese workers: employee motivation in the People's Republic of China. Journal of Organizational Change Management, 11(4), pp. 282-300.

xx. Kanfer, R. \& Chen, G., 2016. Motivation in organizational behavior: history, advances and prospects. Organizational Behavior \& Human Decision Processes, Volume 136, pp. 6-19. 
xxi. Lather, S. \& Jain, S., 2005. Motivation and job satisfaction a study of associates of public and Private sector. Delhi Business Review, 6(1), pp. 77-84.

xxii. Locke, E. \& Latham, G., 1990. A theory of goal setting \& task performance. s.l.:Prentice Hall Inc.

xxiii. McClelland, D., 1987. Human motivation. Cambridge: Cambridge University Press.

xxiv. Mitchell, T., 1982. Motivation: New directions for theory, research, and practice.. Academy of management review, 7(1), pp. 80-88.

xxv. Oudeyer, P. \& Kaplan, F., 2008. How can we define intrinsic motivation, s.l.: Proc. 8th Int.Conf. Epigenetic Robot.: Modeling Cogn. Develop. Robot. Syst..

xxvi. Pei 裴瑞敏, 李. \&\&高艳玲, 2013. 领导风格对科研团队成员创造力的影响机制研究一一内部动机和 LMX 的中介作用. 管理评论, Volume 3, pp. 111-118.

xxvii. Ryan, R. \& Deci, E., 200o. Self-determination theory and the facilitation of intrinsic motivation, social development, and well-being. American psychologist, 55(1), p. 68.

xxviii. Stein, M., 1953. Creativity and culture. The journal of psychology, 36(2), pp. 311-322.

xxix. Sternberg, R. \& Lubart, T., 1991. An investment theory of creativity and its development. Human Development, Volume 34, pp. 1-32.

xxx. Wang, D., Xue, H. \& Su, H., 2010. Influence of work support on employee creativity: An empirical examination in the Peoples Republic of China. African journal of business Management, 4(8), p. 1546.

xxxi. Wei, J., Lu, L. \& Francesco, C., 2010. A cognitive model of intra-organizational knowledgesharing motivations in the view of cross-culture. International Journal of Information Management, 30(3), pp. 220-230.

xxxii. Yang, K., 1986. Chinese personality and its change. In: M. Bond, ed. The psychology of the Chinese People. New York: Oxford University Press, p. 86.

xxxiii. 张弘韬, Z., 2014. 设计师创意驱动力研究-一基于设计管理的视角, s.l.: 武汉理工大学.

xxxiv. 江静, J. \&\&杨百寅, 2014. 领导一成员交换, 内部动机与员工创造力一一工作多样性的调节作用. 科 学学与科学技术管理, 35(1), pp. 165-172.

xxxv. 王艳子, W. \&\&李倩, 张., 2015. 学习目标取向对员工创新行为的影响研究: 内在动机和创新效能感 的中介效应. 现代管理科学, Volume 12, pp. 43-45.

xxxvi. 郭桂梅, G. \&\&段兴民, 2008. 变革型领导行为与创造性: 内在动机和创造性工作氛围的中介作用一 一针对中国企业管理实践的分析. 科学学与科学技术管理, 29(3), pp. 189-196.

xxxvii. 钟敏, Z., 2013. 伦理型领导对员工创造力影响的实证研究, s.l.: 浙江大学. 